\title{
Immune Check Point CD40-CD40L Activates Dendritic and Effector Cells Against Human Renal Carcinoma Cells
}

\author{
REGINA M. HILLEBRAND ${ }^{1}$, ANNABELLE VOGT ${ }^{2}$, CHRISTIAN P. STRASSBURG ${ }^{2}$, \\ MARIA A. GONZALEZ-CARMONA ${ }^{2 *}$ and INGO G.H. SCHMIDT-WOLF ${ }^{*}$ \\ ${ }^{1}$ Department of Integrated Oncology, University of Bonn, Bonn, Germany; \\ ${ }^{2}$ Department of Internal Medicine I, University of Bonn, Bonn, Germany
}

\begin{abstract}
Background/Aim: Adenoviral-mediated expression of CD40 ligand (CD40L) on dendritic cells (DCs) activates immune check point CD40/CD40L, enhancing the immunostimulation of DCs and effector cells against human renal carcinoma cells (RCC) and inducing tumor cell apoptosis in vitro. Materials and Methods: DCs, isolated from buffy coats from healthy donors, were transduced with adenoviruses carrying human CD40L (Ad-hCD40L). Subsequently maturation marker and cytokine expression were analyzed by fluorescence-activated cell sorting and enzyme-linked immunosorbent assay. Results: Adenoviral transduction induced high expression of soluble CD4OL and membrane-bound CD40L, leading to a strong CD40-CD40L interaction in DCs. Interestingly, a T-helper cell type 1 shift of expressed cytokines/chemokines was observed due to the expression of membrane-bound CD4OL rather than due to soIuble CD4OL alone, which significantly reduced immunoactivation of DCs. However, supernatants of Ad-hCD40L-transduced DCs induced apoptosis of RCC cells. Co-culture of Ad-hCD4OL DCs with cytokine-induced killer cells led to a significant stimulation of tumor-specific cytokine-induced killer cells, with increased proliferation and cytotoxicity. Conclusion: Use of Ad-hCD4OLtransduced DCs is a promising approach to treating $R C C$.
\end{abstract}

Renal cell carcinoma (RCC) is often asymptomatic and already metastatic at the time of diagnosis. It is also usually resistant to conventional chemotherapy (1). Improved knowledge about the molecular biology of RCC has led to the development of

*These Authors contributed equally to this study.

Correspondence to: Ingo G.H. Schmidt-Wolf, Department of Integrated Oncology, Center for Integrated Oncology ABCD, University Hospital of Bonn, Venusberg-Campus 1, D-53127 Bonn, Germany. Tel: +49 22828717050, Fax: +49 22828717065, e-mail: ingo.schmidt-wolf@ukbonn.de

Key Words: CD40 ligand, dendritic cells, immune checkpoint, renal cancer. targeted therapies, such as application of inhibitors of vascular endothelial growth factor and mechanistic target of rapamycin (e.g. sunitinib, bevacizumab, and temsirolimus). Targeted therapies have shown significant clinical efficacy in trials on patients with metastatic RCC (2). However, complete remission and long-lasting survival have only rarely been observed with these therapies (3). Immunotherapeutic strategies (e.g. interleukin (IL) 2) have been much more promising. Moreover, the successful application of nivolumab, an inhibitor of programmed cell death protein 1 (PDCD1), has indicated that RCC is, in fact, susceptible to immunotherapy (4-6).

The use of dendritic cell (DC)-based vaccines as cancer immunotherapy has been shown to be an attractive approach for the treatment of solid tumors in a preclinical setting. DCs are professional antigen-presenting cells with the ability to initiate and modulate immune response by activating B- and T-lymphocytes. DCs may, therefore, play an essential role in the development of therapeutic immunity against cancer (79). Several phase I and II trials applying DC-based vaccines in different types of cancer, including RCC (10-14), have shown that side-effects are only mild, such as local reactions, fever and flu-like symptoms (12). CD40 ligand (CD40L) is a co-stimulatory molecule which is usually expressed on activated immune cells, especially on CD4 ${ }^{+}$T-helper (Th) cells. The interaction with its receptor CD40, which is expressed on DCs, primes cytotoxic T-cells (15). DC maturation, essential for antitumor immunity (16) and proinflammatory cytokine production, is enhanced by CD40CD40L interaction.

In this study, adenovirally delivered CD40L was used to activate the immune check point CD40-CD40L to improve the immunomodulatory potential of DCs for the immunotherapy of RCC.

\section{Materials and Methods}

Cell lines. 911 cells were used for adenovirus production (17). The human RCC cell lines Caki-2 (ATCC HTB-47; ATCC, Manassas, VA, USA), A-498 (ATCC HTB-44) and A-704 (ATCC HTB-45) were used for experiments. 911 and RCC cells were 
cultured in Dulbecco's modified Eagle's medium (Life Technologies GmbH, Darmstadt, Germany) and RPMI-1640 (PAA, Cölbe, Germany) with $10 \%$ fetal calf serum (FCS) (Life Technologies $\mathrm{GmbH}), 100$ units $/ \mathrm{ml}$ penicillin and $100 \mu \mathrm{g} / \mathrm{ml}$ streptomycin (Sigma-Aldrich, München, Germany). A-704 cells were additionally cultured with $0.02 \%$ insulin (Lilly, Bad Homburg, Germany).

Adenoviral vectors. Two different adenoviruses (Ad) with deletion of E1 gene were generated using the Ad-Easy System as previously described (18) carrying wild-type (Ad-Mock) or human CD40L (Ad-hCD40L). For adenovirus stocks, 911 cells were transduced with adenoviruses at a multiplicity of infection (MOI) of 1. Plaque assays were performed according to Graham and Prevec (19) to determine viral titers.

Production of tumor-cell lysate and determination of protein concentration. Caki-2, A-498 and A-704 cells were harvested and subjected to three cycles of freezing and thawing. After centrifugation, the supernatant was collected and its protein concentration was determined with BCA protein detection kit (Thermo, Bonn, Germany), according to the manufacturer's instructions.

Generation and Ad transduction of DCs. Peripheral blood mononuclear cells were isolated from buffy coat from healthy donors after receiving informed consent as described previously (18). Density-gradient centrifugation was used to generate monocyte-derived DCs with OptiPrep Density Gradient Medium (Sigma-Aldrich). DCs were cultured in RPMI-1640 medium with $10 \%$ autologous, heat-inactivated serum with $750 \mathrm{U} / \mathrm{ml}$ granulocyte macrophage colony-stimulating factor (Immunotools, Friesoythe, Germany) and $500 \mathrm{U} / \mathrm{ml}$ IL4 (Immunotools). On day 5 of cultivation, cell lysate $(100 \mu \mathrm{g} / \mathrm{ml})$ prepared as described above was added. DCs were transduced with adenoviruses on day 6 of cultivation with MOI 100 for $2 \mathrm{~h}$.

Generation of cytokine-induced killer (CIK) cells and co-culture with DCs. Human CIK cells were generated as described previously (18). Peripheral blood mononuclear cells were cultured with 1,000 $\mathrm{U} / \mathrm{ml}$ interferon gamma (IFN $\gamma$; Immunotools). After $24 \mathrm{~h}, 50 \mathrm{ng} / \mathrm{ml}$ anti-CD3 (eBioscience, Frankfurt, Germany), $100 \mathrm{U} / \mathrm{ml}$ IL1B and $300 \mathrm{U} / \mathrm{ml}$ IL2 (Immunotools) were added. DCs were pulsed with cell lysates from Caki-2, A-498 or A-704 cells on day 5 and transduced on day 6 . Starting on day 8 of cultivation, CIK cells were co-cultured for 4 days with DCs at a ratio of 1:5 and tested for their cytotoxicity.

Surface marker analysis of DCs and CD40 expression of RCC cells. Forty-eight hours after transduction, on day 8 of cultivation, DCs were immunophenotyped by flow cytometry. Expression of CD40 was also analyzed by flow cytometry. Monoclonal antibodies specific for human CD83, CD86, CD40L (Pharmingen, Hamburg, Germany), C-C motif chemokine receptor 7 (CCR7) (R\&D Systems, Wiesbaden, Germany), CD40 and CD80 (eBioscience, Frankfurt, Germany) were used together with their isotype-matched monoclonal antibodies as control. 4'-6-Diamidino-2-phenylindole (DAPI) was used to distinguish between living and dead cells, with 30,000 events for each sample with a FACS Canto 11 using Diva Software and analyzed with FlowJo 7.2.2 (Tree Star Inc., Ashland, OR, USA).
Measurement of cytokine levels. Levels of cytokines usually expressed by mature DCs were measured in the supernatant of DCs or in the supernatant of CIK cells co-cultured with Ad-hCD40L DCs by enzyme-linked immunosorbent assay (ELISA; eBioscience) or by cytokine array (R\&D System, Wiesbaden, Germany), according to the manufacturer's instructions.

Blocking of CD40-CD40L interaction of DCs. DCs were transduced with Ad-hCD40L on day 6 of cultivation. Cells were incubated with different concentrations of an anti hCD40L blocking antibody or a control isotype antibody (R\&D Systems, Wiesbaden, Germany) for 2 days. Subsequently IL12 levels in the supernatant were measured by ELISA.

Transwell assay. The effect of soluble (s)CD40L in the supernatant of DCs was analyzed in transwell assays. After transduction with Ad-Mock or Ad-hCD40L, DCs were seeded in the upper compartment of a transwell chamber $(1 \mu \mathrm{m}$ pore size; Corning Costar, Cambridge, MA, USA), carrying Ad-Mock DCs as control in the bottom compartment. After $48 \mathrm{~h}$ of incubation, cells in the bottom compartment were washed twice and further incubated for $48 \mathrm{~h}$ in order to analyze cytokine production. The cytokine levels in the supernatant were analyzed by ELISA and cells were analyzed for surface marker expression by flow cytometry.

Apoptosis detection. RCC cell lines were cultured for $48 \mathrm{~h}$ with DC supernatants. Subsequently, the subG1 fraction was analyzed by flow cytometry to quantify the apoptosis rate.

3-(4,5-Dimethylthiazol-2-yl)-2,5-diphenyltetrazoliumbromid (MTT) cell proliferation assay. Cell proliferation of effector cells (CIK) after co-culture with transduced DCs was quantified in MTT tests with tetrazolium after 0,48 and $96 \mathrm{~h}$ of co-culture. Co-cultured cells were then separated by centrifugation. The pellet was dissolved in $100 \mu \mathrm{l}$ MTT solution and the supernatant was removed after $45 \mathrm{~min}$. The colored crystal was dissolved in $100 \mu$ l dimethyl sulfoxide and absorbance was then measured at $550 \mathrm{~nm}$ after $5 \mathrm{~min}$ of incubation.

Cytotoxicity assay. Cytotoxicity of co-cultured CIK cells towards tumor cells was analyzed using Cytotox-One Homogeneous Membrane Integrity Assay (Promega, Mannheim, Germany) according to the manufacturer's instructions. Target cells were incubated with different effector cell ratios (1.25:1, 2.5:1, 5:1, 10:1, $20: 1,40: 1,80: 1)$ for $4 \mathrm{~h}$. Maximum release was obtained by incubating target cells with lysis buffer. Target cells without effector cells served as negative control (spontaneous release). Specific lysis was calculated as follows: Cytotoxicity $(\%)=($ experimental release - spontaneous release)/(maximal release - spontaneous release).

Statistical analysis. Data represent means and standard errors of the mean (SEM) from 2-7 independent experiments. Statistical significances were calculated in paired $t$-tests. Differences with a $p$ value of less than 0.05 were considered significant.

\section{Results}

DC are activated upon transduction with adenoviruses carrying human CD4OL (Ad-hCD40L). To analyze the immunogenic capacity of CD40L several experiments were performed. Upon transduction, transgene expression of 


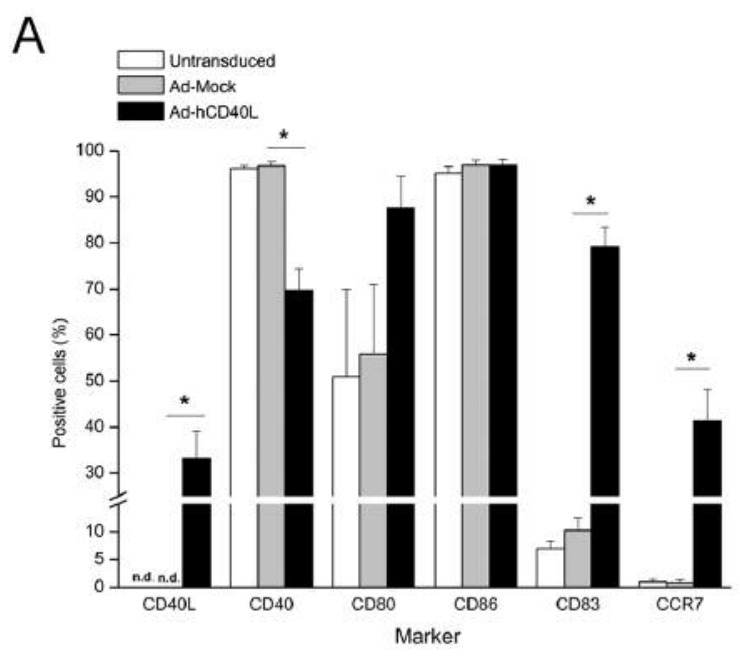

B

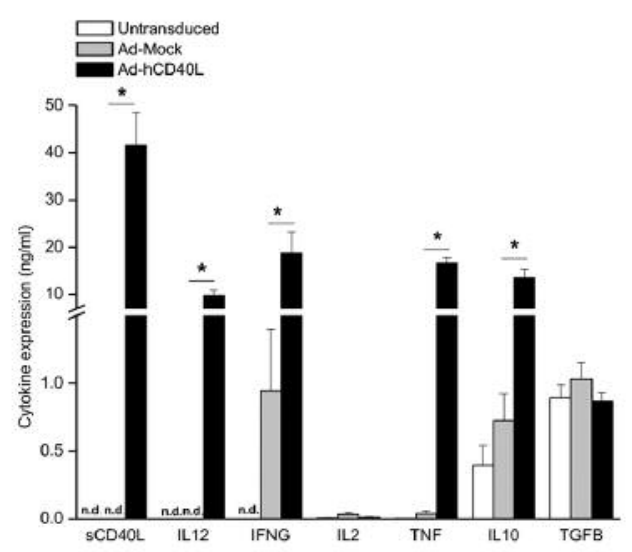

CD40L was detected in $33.1 \pm 6.0 \%$ of the Ad-hCD40L DCs Expression of CCR7 and CD83 on DCs was significantly increased, while the expression of CD40 was significantly reduced (Figure 1A). In correspondence with the high level of membrane-bound CD40L, Ad-hCD40L DCs produced an equally high level of sCD40L (Figure 1B). Of note, forced CD40L expression also significantly increased the IL12 level in the supernatant from cultures of Ad-hCD40L DCs. Other Thelper cell type 1 (Th1) related cytokines, such as IFN $\gamma$, tumor necrosis factor (TNF) and IL2, were also significantly increased, as were T-helper cell type 2 (Th2) cytokines such as IL10 in supernatant from cultures of Ad-hCD40L DCs (Figure 1B). As a sign of the interaction between CD40 and CD40L, DCs transduced with Ad-hCD40L started to clot in our preparations a few hours after transduction, whereas no aggregate formation was observed in DCs transduced with AdMock. Because of this observation, CD40L was blocked with

\section{C}

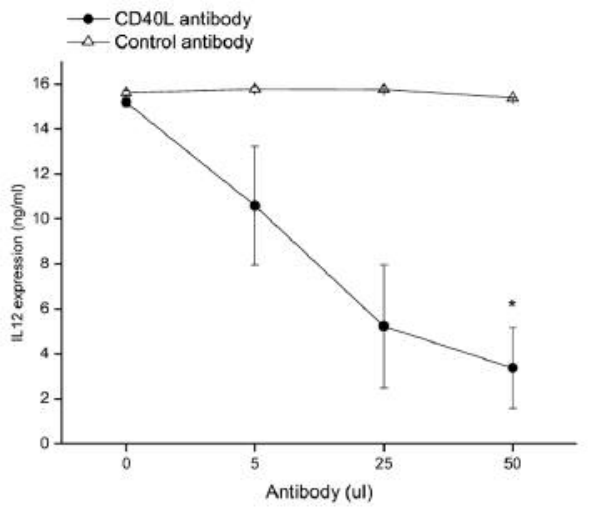

Figure 1. Immune activation of dendritic cells (DCs) after transduction with adenovirus carrying human CD4OL (Ad-hCD4OL) and blocking of CD40. Ad-Mock and untransduced DC as control group. A: Expression of surface markers CD40 ligand (CD40L), CD40, CD80, CD86 and C$C$ motif chemokine receptor (CCR7) on DCs 48 h after adenoviral transduction. B: Cytokine amounts of soluble (s) CD4OL, Interleukin (IL) 12, interferon gamma (IFNG), IL2, tumor necrosis factor (TNF), IL10 and transforming growth factor beta (TGFB) measured in the supernatant from cultures of DCs analyzed on day 8 after DC generation. C: IL12 levels in supernatant from cultures of DCs. DCs were transduced with $A d-h C D 40 L$ and subsequently antibody to human CD40L was added at different concentrations (5, 25 and 50ul). Results represent the mean and standard error of the mean (SEM) from six, seven and four independent experiments, respectively. n.d.: Not detectable. *Significantly different at $p<0.05$. different concentrations of a blocking antibody directly after transduction, and the resulting aggregate formation and corresponding IL12 expression were analyzed. As expected, DCs treated with blocking antibody failed to form aggregates. In line with this, IL12 expression was significantly reduced (Figure 1D).

Furthermore, the expression of Th1 cytokines and chemokines, such as C-C motif chemokine ligand (CCL) 3 and 4 was significantly increased upon transduction as measured on cytokine arrays. Levels of IL6, IL17, IL25 and IL23 were also increased upon transduction (Figure 2). Moreover, we discovered Ad-hCD40L induced expression of CCL5 and colony-stimulating factor 3 (Figure 2).

Influence of Th1-shifted supernatant on DCs after Ad-hCD40L transduction. To analyze if the Th1 environment generated from Ad-hCD40L DCs may result in immunoactivation of 
A

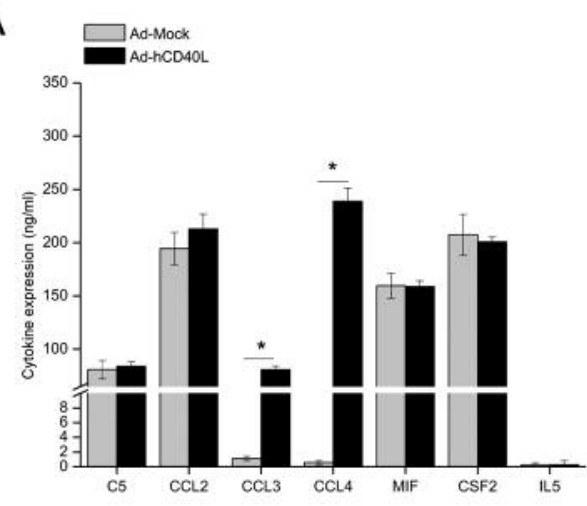

C

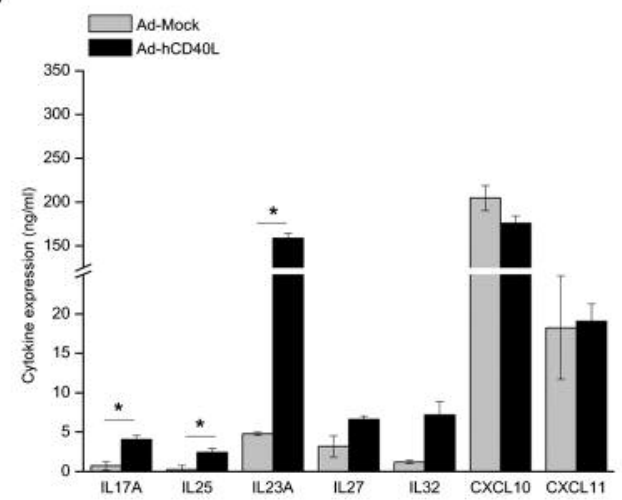

B

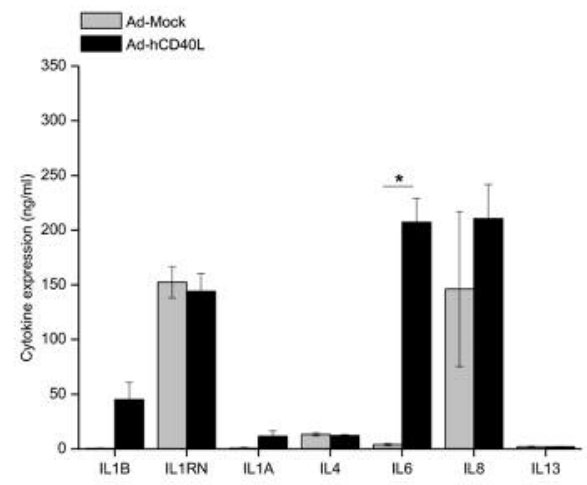

D

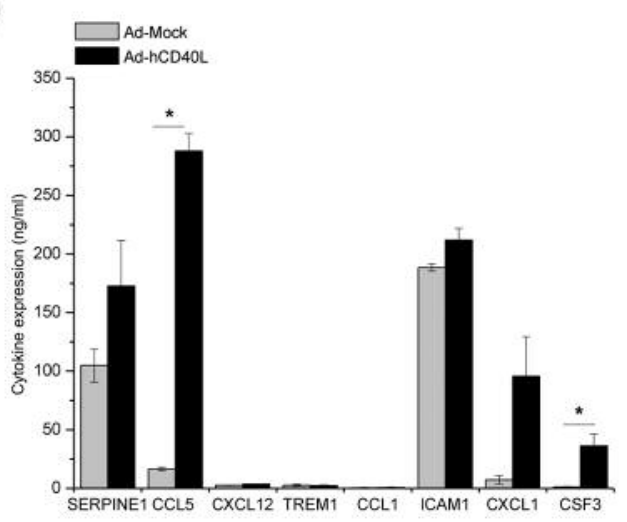

Figure 2. Cytokine and chemokine levels of dendritic cells (DCs) determined by cytokine array after their activation with adenovirus carrying human CD40L (Ad-hCD40L). Ad-Mock and untransduced DC as control group. A-D Cytokine and chemokine amounts of complement C5 (C5), C-C motif chemokine ligand (CCL) 2, CCL3, CCL4, macrophage migration inhibitory factor (MIF), colony stimulating factor 2 (CSF2), IL5, IL1B, interleukin 1 receptor antagonist (IL1RN), IL1A,IL4,IL6,IL8,IL13,IL17A, IL25, IL23A, IL27, IL32, C-X-C motif chemokine ligand (CXCL) 10, CXCL 11, serpin family E member 1 (SERPINE1), CCL5, CXCL12, triggering receptor expressed on myeloid cells 1 (TREM1), CCL1, intercellular adhesion molecular 1 (ICAM1), CXCL1 and colony stimulation factor 3 (CSF3) measured in the supernatant of DCs. Results represent the mean and SEM of four different experiments. n.d.: Not detectable. *Significantly different at $p<0.05$.

DCs, we analyzed the influence of supernatant from cultures of Ad-hCD40L DCs on Ad-Mock DCs using transwell assays. Supernatant from cultures of Ad-Mock-transduced DCs was used as control instead of commercially available sCD40L to rule out transduction-influenced effects and verify a purely CD40L-triggered effect. As expected, treatment of Ad-Mock DCs with supernatant from cultures of Ad-hCD40L DCs significantly increased expression of CD80, CD83 and CCR7 (Figure 3A). However almost no Th1 cytokine expression (IL12 or IFN $\gamma$ ) was detectable compared to the high expression levels achieved through direct cellular CD40CD40L interaction upon Ad-hCD40L transduction (Figure $3 \mathrm{~B})$. This indicates that direct cellular contact is more effective.

Influence of Th1-shifted supernatant on RCC cells. The supernatant of Ad-hCD40L DCs induced a significant increase of the subG ${ }_{1}$ cell population, as a sign of apoptosis, in all RCC cell lines (Figure 4A-C). The proportion of cells expressing CD40 was high in all RCC cell lines (Figure 4A).

Influence of Ad-hCD4OL DCs on CIK cells. As shown in Figure 5, CIK cells co-cultured with Ad-hCD40L DCs had significantly higher cell proliferation than did the controls for all cell lines tested. Additionally, we tested the influence of Ad-hCD40L DCs on the cytokine expression of CIK effector cells. Th1-related IFN $\gamma$ was also clearly increased in all co-cultures of CIK cells with Ad-hCD40L transduced DCs (Figure 5D).

Influence of Ad-hCD4OL DCs on cytotoxicity of CIK cells towards RCC cells. As shown in Figure 6, cytotoxicity of CIK cells towards all RCC cell lines was increased after coculture with Ad-hCD40L DCs. 
A

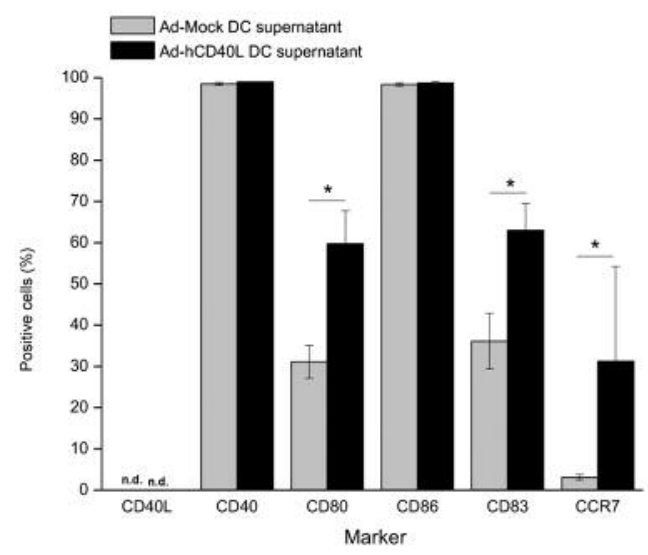

B

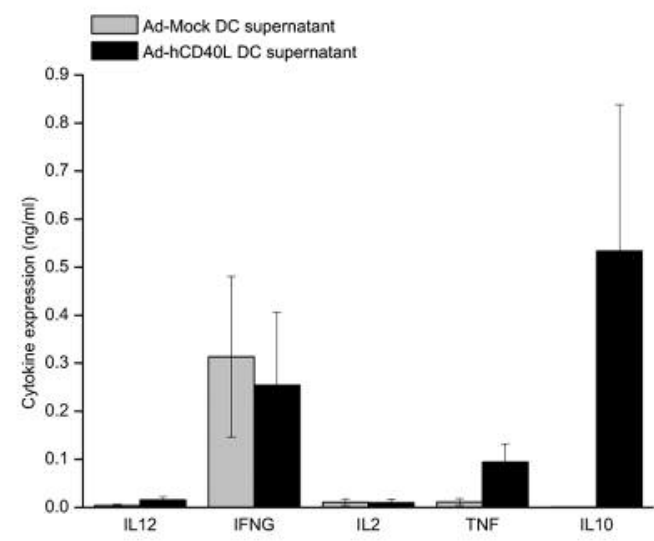

Figure 3. Influence of T-helper cell type 1-shifted supernatant from cultures of dendritic cells (DCs) after transduction with adenovirus carrying human CD4OL (Ad-hCD4OL) on Ad-Mock DCs. Ad-Mock DCs were cultured with Ad-Mock DCs as control. A: Flow cytometry of DC surface markers (CD40L, CD40,CD80, CD86, CD83, CCR7) 48 h after incubation of Ad-Mock DCs with Ad-hCD40L DCs in a transwell. B: Cytokine amounts of IL12, IFNG, IL2, TNF and IL10 measured for the above described transwell experiment. Results represent the mean and SEM of four different experiments. $n . d .:$ Not detectable. ${ }^{*}$ Significantly different at $p<0.05$.

\section{Discussion}

In this study, we showed that adenoviral transduction of DCs with human CD40L (Ad-hCD40L) induced a CD40-CD40Ldependent cellular interaction of DCs, leading to significant up-regulation of maturation markers and a significant shift to expression of Th1-related cytokines and chemokines. These immunoactivated DCs were able to induce a strong Th1-shifted environment capable of increasing the cytotoxicity of effector cells, such as CIK cells. We showed that this effect is dependent on the expression of membranebound CD40L, through cellular interaction among DCs, rather than $\mathrm{SCD} 40 \mathrm{~L}$, although the supernatant from cultures of Ad-hCD40L-transduced DCs also induced apoptosis of RCC cells in vitro.

DC-based immunotherapy has already been investigated in several studies $(16,20-22)$. CD40L has already been used as a stimulator for DCs $(23,24)$ and, like in our study, has been transduced using adenoviruses $(25,26)$. Outcomes of these studies in RCC are very encouraging and have demonstrated that DCs can induce a cellular immune response and can have a positive clinical benefit (23). Adenoviral transduction is known to enhance expression of co-stimulatory molecules and IL12 on DCs, increasing maturation of DCs and therefore adenoviral vectors were chosen for transgene expression of CD40L in DCs (25-28).

Accordingly, in most of our experiments Ad-Mocktransduced DCs showed higher immunostimulation compared to untransduced DCs. Thus, we chose this technique to improve efficiency of transgene expression of human CD40L on DCs. Loskog et al. showed adenoviralmediated expression of human CD40L in bladder and renal tumor cells to have the capacity to stimulate DCs and, thereby, induce apoptosis (29). Although these results have been very encouraging, direct in vivo transgene expression of CD40L in a patient's tumor cells is, at this point, not feasible. In this study, we therefore engineered ex vivo CD40L-expressing DCs capable of activating and stimulating themselves through CD40-CD40L interaction.

As expected, we achieved high CD40L expression (membrane-bound and soluble) after transduction of DCs with CD40L-encoding adenovirus. In addition, remarkably high expression of CD83, a marker of DC maturation (12), and CCR7, which is necessary for DC migration into draining lymph nodes (30), were detected as a sign of strong immunostimulation. In other studies, CD40 expression was up-regulated on mature DCs $(31,32)$. However, in our study, the CD40 expression of DCs appeared to be diminished after transduction with Ad-hCD40L. A strong CD40-CD40L interaction among the DCs leading to a reduction of free CD40 on DCs may explain the reduced detection of CD40 by flow cytometry. Similar effects were observed in the study of Loskog et al. (29).

Investigating the cytokine levels in supernatant from cultures of Ad-hCD40L-transduced DCs, we sought significantly higher secretion of IL12, IFN $\gamma$ and tumor necrosis factor as a sign of strong Th1 induction. In particular, IL12 is a potent marker of DC activity. In order to demonstrate that the effects described above were CD40L specific, the AdhCD40L-transduced DCs were blocked with a CD40L- 
A

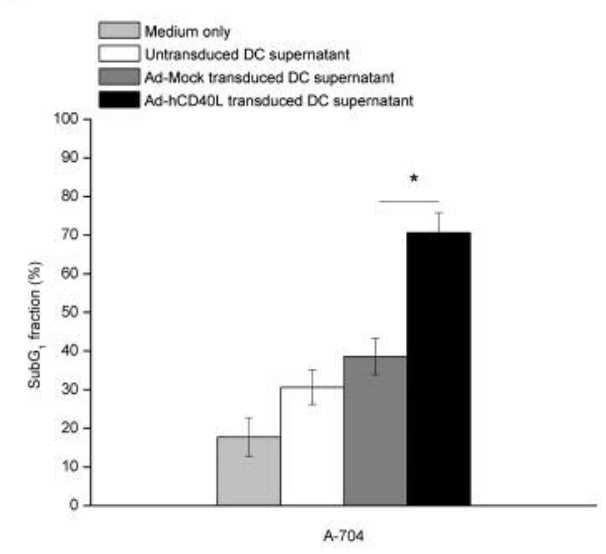

C

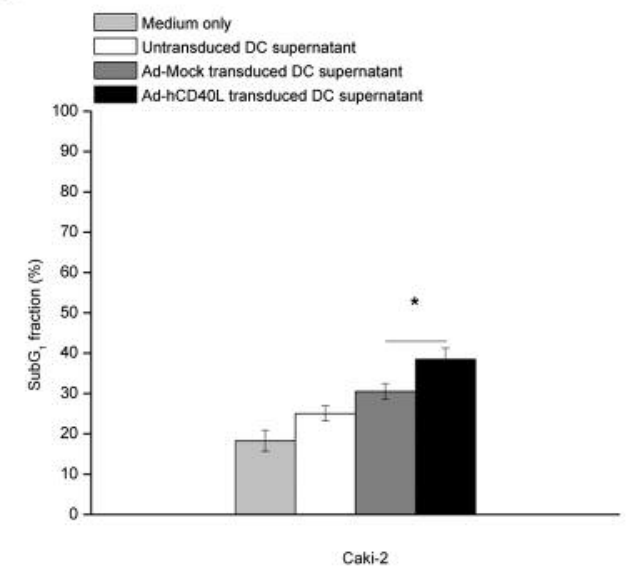

B

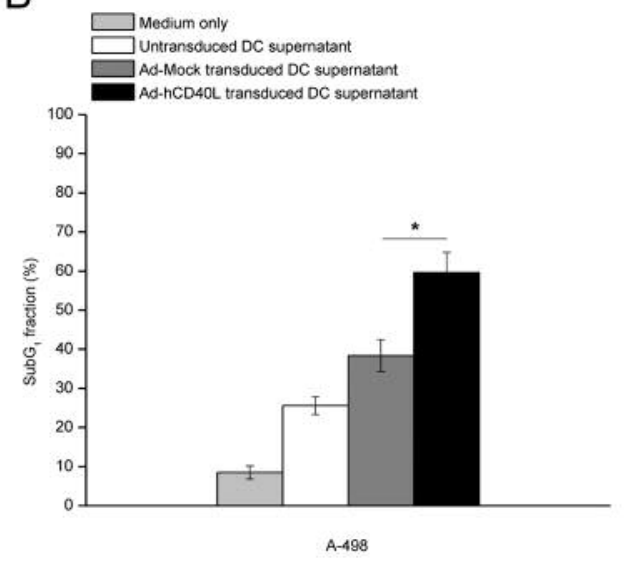

D

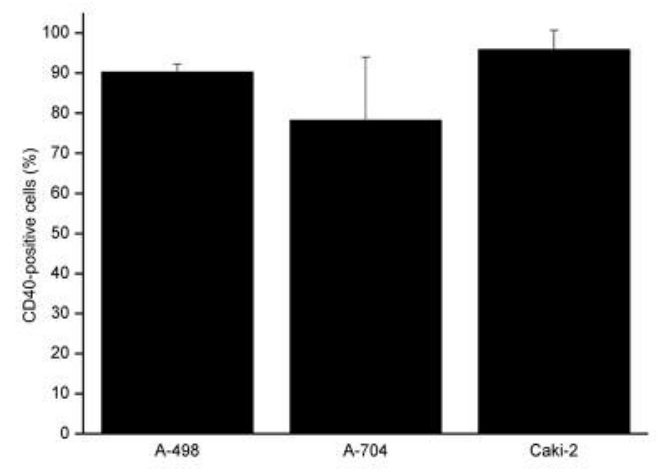

Figure 4. Influence of Th1-shifted supernatant on renal cell carcinoma cells. A-704 (A), A-498 (B) and Caki-2 (C) cells were incubated for 48 h with supernatant from cultures of non-transduced, Ad-Mock-transduced, and adenovirus carrying human CD40L (Ad-hCD40L)-transduced dendritic cells (DCs), and normal medium alone as control. Accordingly, cells were harvested, and the subG $G_{1}$ fraction was measured by flow cytometry. Results represent mean and SEM from four independent experiments. Measurements were performed as triplicates. D: CD40 expression on A-498, A-704 and Caki-2 analyzed by flow cytometry. The results show the mean and SEM of three different experiments. *Significantly different at p<0.05.

blocking antibody directly after transduction. As a result, we did not detect any aggregates and observed significantly reduced IL12 production. These results imply that CD40CD40L interactions among the DCs are responsible for their strong immunostimulation.

Expression of CCL3 and -4 , chemokines that can modulate DC movement and maturation (7), was also significantly increased in the supernatant of DCs after transduction with Ad-hCD40L, as was that of IL6, IL17, IL23, IL25 and colony-stimulating factor 3. All these cytokines are usually expressed by mature DCs and via CD40-CD40L interaction (33).

However, the CD40-CD40L interaction also induced high levels of T-helper cell type 2 (Th2) cytokines, such as IL10, which is known to inhibit the production of Th1 cytokines and is usually associated with immature or semimature DCs (34). This demonstrates that CD40 activation of DCs can induce both Th1 and Th2 immune responses, including IL10 secretion.

Kim et al. used sCD40L to achieve DC maturation and obtained promising results in patients with metastatic RCC (12). In our study, adenoviral transduction with Ad-hCD40L induced secretion of $\mathrm{sCD} 40 \mathrm{~L}$ and a high expression of membrane-bound CD40L on the surface of DCs. In order to dissect the effects of the supernatant of Ad-hCD40L DCs with high levels of sCD40L and Th1 cytokines on neighboring DCs, transwell experiments with Ad-Mock DCs in contact with the supernatant from cultures of Ad-hCD40L DCs were 
A

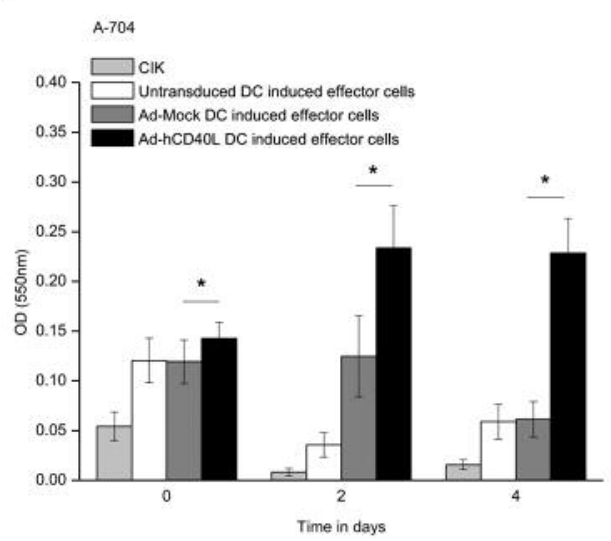

C

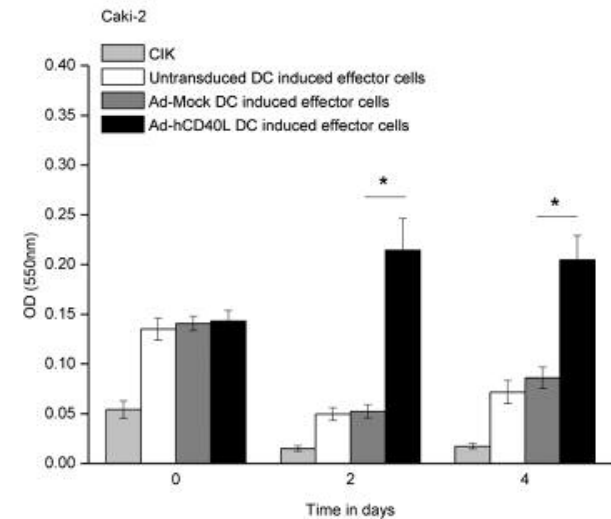

B

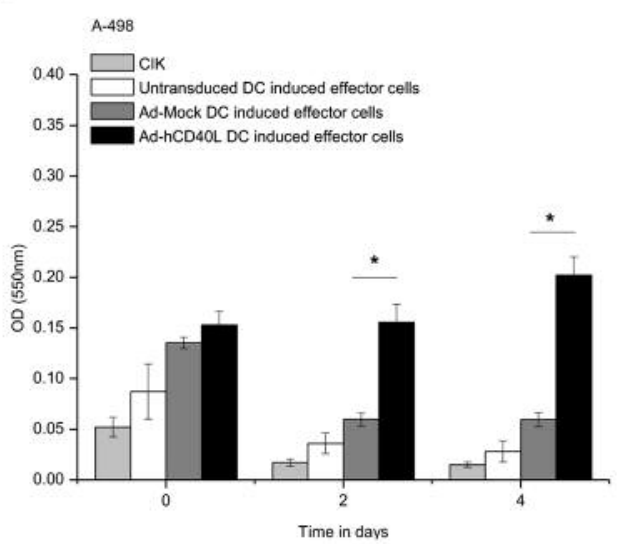

D

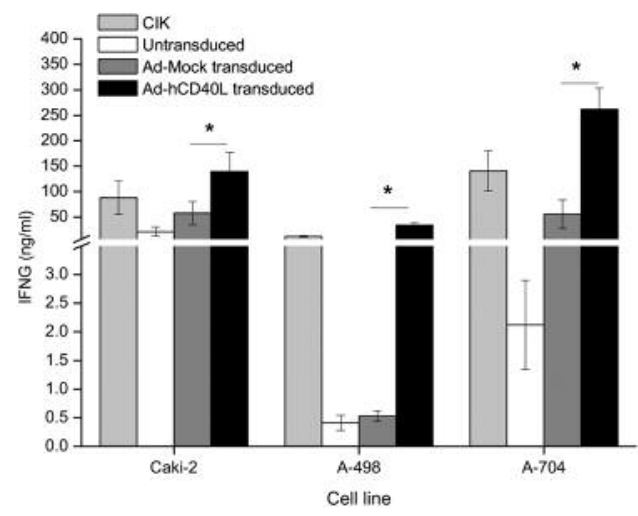

Figure 5. Influence of dendritic cells (DCs) transduced with adenovirus carrying human CD40L (Ad-hCD40L) on the proliferation of cytokine induced killer (CIK) cells (A-C) and interferon gamma (IFN $\gamma)$ expression (D). Quantification of cell proliferation of effector cells (CIK) co-cultured with non-transduced, Ad-Mock-transduced, and Ad-hCD4OL-transduced DCs and of CIK cells alone by 3-(4,5-Dimethylthiazol-2-yl)-2,5diphenyltetrazoliumbromid test on day 0, 2 and 4 of quadruplicate co-cultures. The DCs were pulsed with lysate from A-704 (A), A-498 (B) or Caki-2 (C) cells before co-culture. D: IFN $\gamma$ was measured in the supernatant of DCs pulsed with cell lysates from Caki-2, A-498 or A-704 cells and then co-cultured with CIK cells for 4 days. Data are shown as the mean \pm standard error of the mean from two independent experiments. *Significantly different at $p<0.05$.

performed. It became obvious that the supernatant of AdhCD40L DCs significantly increased the expression of maturation markers CD80, CD83 and CCR7, but not as strongly as direct CD40-CD40L interaction. Furthermore, the supernatant of Ad-hCD40L DCs alone was not able to induce Th1 cytokine expression on neighboring DCs. This clearly shows that intercellular contact of DCs via CD40-CD40L by the expression of membrane-bound CD40L is necessary for the induction of stronger immunostimulation of DCs and represents an improvement of DC activation compared to sCD40L alone. In conclusion, with our method even better results might be achieved in patients with metastatic RCC.

Previous studies have shown that human RCC cells express CD40, that is associated with prolonged survival
(35) and might be a possible target for new therapies. It has been shown that CD40 activation induced apoptosis in mouse RCC (33). In our study, the three selected human RCC cell lines A-704, A-498 and Caki-2 showed high CD40 expression. From the data presented, we detected a significantly higher rate of apoptosis in all RCC cell lines after their incubation with supernatant from cultures of AdhCD40L DCs (containing sCD40L) compared to the control group. This outcome suggests that Ad-hCD40L DCs can induce apoptosis of CD40-expressing RCC cells, probably through sCD40L-related CD40 stimulation but also through other factors such as cytokines like IFN $\gamma$.

In addition, we also demonstrated a strong influence of AdhCD40L-transduced DCs on CIK cells. CIK cells are very 
A

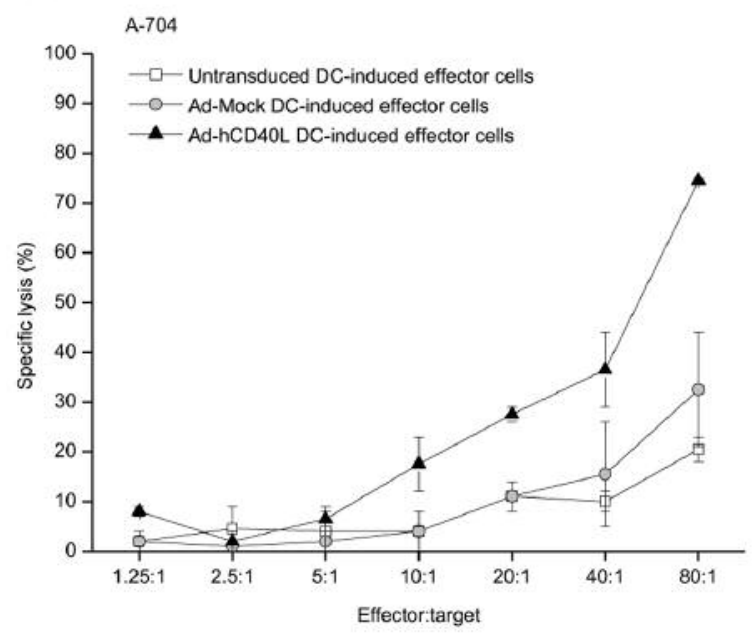

B

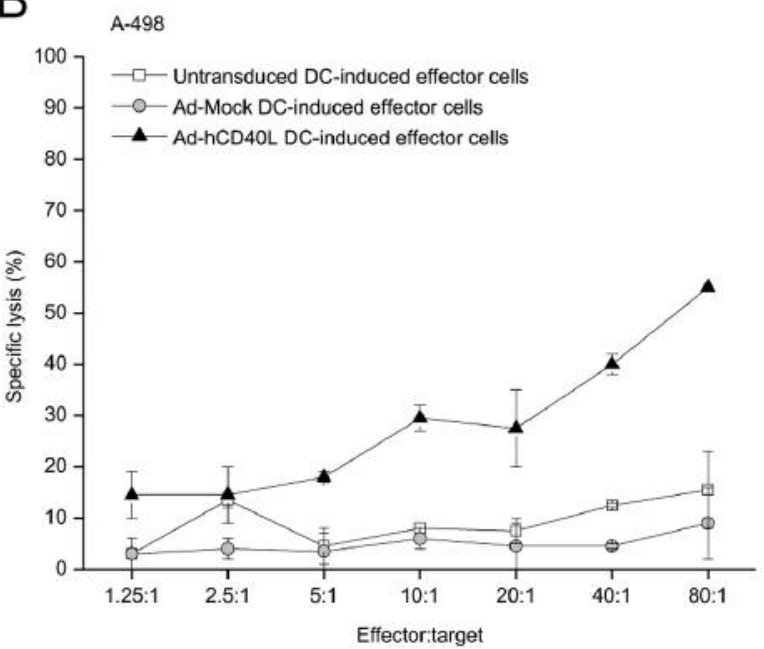

effectively cytotoxic, and are able to lyse tumor cell targets (36). They already showed promising effects against RCC and other tumor entities in several studies (37-40). In this study, co-culture of CIK cells with Ad-hCD40L DCs induced a significant improvement of the immunomodulatory capacity of CIK cells by enhancing Th1 cytokine expression, proliferation and cytotoxicity towards RCC cells. We explicitly detected a shift towards a Th1 cytokine profile with increased IFN $\gamma$ secretion.

Thus, Ad-hCD40L transduced DCs appear to be a promising method for treating RCC, and further experiments in vivo are planned to further investigate these findings.

\section{Conflicts of Interest}

This study did not receive any specific grant from funding agencies in the public, commercial, or not-for-profit sectors. There are no conflicts of interest in regard to this study.

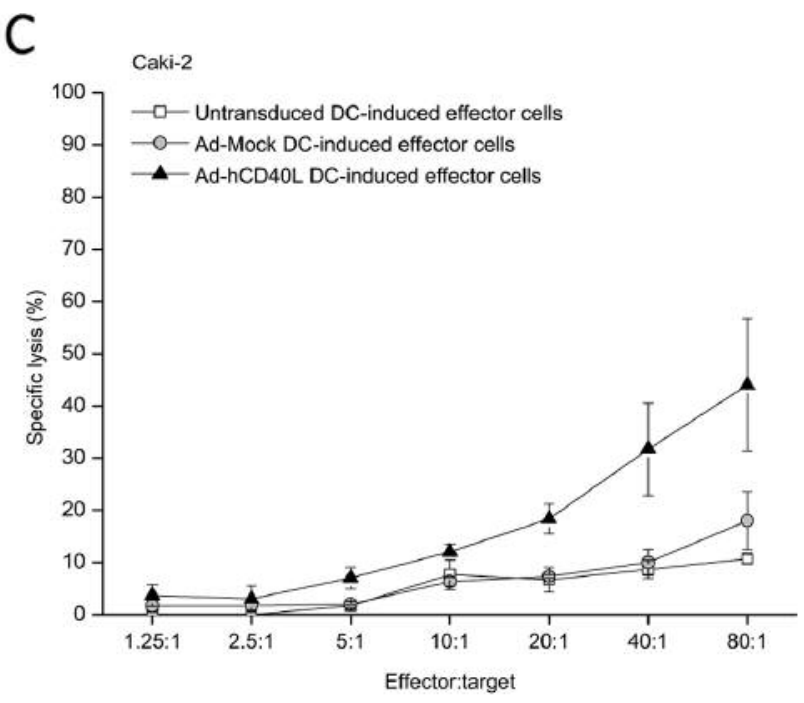

Figure 6. Influence of dendritic cells (DCs) transduced with adenovirus carrying human CD4OL (Ad-hCD40L) on cytotoxicity of cytokine induced killer $(C I K)$ cells towards renal cell carcinoma cells. On day 6 of their generation, DCs were adenoviral transduced with Ad-hCD4OL or Ad-Mock at multiplicity of infection of 100 and afterwards cocultured with CIK cells as effector cells for 4 days. A-704 (A), A-498 (B) and Caki-2 (C) cells were used as targets and the cytotoxicity of the effector cells (CIK) was measured at different effector-to-target cell ratios $(E: T)$. Data are shown as mean \pm standard error of the mean from two independent experiments each performed in triplicate.

\section{Authors' Contributions}

Regina M. Hillebrand and Annabelle Vogt carried out the experiments. Regina M. Hillebrand wrote the article with support from Maria A. Gonzalez-Carmona and Ingo G.H. Schmidt-Wolf both designed the study. Christian P. Strassburg helped supervise the project.

\section{References}

1 Yagoda A, Petrylak D and Thompson S: Cytotoxic chemotherapy for advanced renal cell carcinoma. Urol Clin North Am 20: 303-321, 1993. PMID: 8493752.

2 Atkins MB, Bukowski RM, Escudier BJ, Figlin RA, Hudes GH, Kaelin WG, Linehan WM, McDermott DF, Mier JW, Pedrosa I, Rini BI, Signoretti S, Sosman JA, Teh BT, Wood CG, Zurita AJ and King L: Innovations and challenges in renal cancer: summary statement from the Third Cambridge Conference. Cancer 115: 2247-2251, 2009. PMID: 19402064. DOI: 10.1002/ cncr.24229 
3 Thomas JS and Kabbinavar F: Metastatic clear cell renal cell carcinoma: A review of current therapies and novel immunotherapies. Crit Rev Oncol Hematol 96: 527-533, 2015. PMID: 26299335. DOI: 10.1016/j.critrevonc.2015.07.009

4 Bukowski RM: Immunotherapy in renal cell carcinoma. Oncol Williston Park N 13: 801-810; discussion 810, 813, 1999. PMID: 10378218.

5 Glaspy JA: Therapeutic options in the management of renal cell carcinoma. Semin Oncol 29: 41-46, 2002. PMID: 12068388.

6 Motzer RJ, Rini BI, McDermott DF, Redman BG, Kuzel TM, Harrison MR, Vaishampayan UN, Drabkin HA, George S, Logan TF, Margolin KA, Plimack ER, Lambert AM, Waxman IM and Hammers HJ: Nivolumab for metastatic renal cell carcinoma: Results of a randomized phase II Trial. J Clin Oncol 33: 14301437, 2015. PMID: 25452452. DOI: 10.1200/JCO.2014.59.0703

7 Banchereau J and Steinman RM: Dendritic cells and the control of immunity. Nature 392: 245-252, 1998. PMID: 9521319. DOI: $10.1038 / 32588$

8 Palucka K, Ueno H, Fay J and Banchereau J: Dendritic cells and immunity against cancer. J Intern Med 269: 64-73, 2011. PMID: 21158979. DOI: $10.1111 /$ j.1365-2796.2010.02317.x

9 Steinman RM: Decisions about dendritic cells: past, present, and future. Annu Rev Immunol 30: 1-22, 2012. PMID: 22136168. DOI: 10.1146/annurev-immunol-100311-102839

10 Schwaab T, Schwarzer A, Wolf B, Crocenzi TS, Seigne JD, Crosby NA, Cole BF, Fisher JL, Uhlenhake JC, Mellinger D, Foster C, Szczepiorkowski ZM, Webber SM, Schned AR, Harris RD, Barth RJ, Heaney JA, Noelle RJ and Ernstoff MS: Clinical and immunologic effects of intranodal autologous tumor lysatedendritic cell vaccine with aldesleukin (interleukin 2) and IFN\{alpha\}2a therapy in metastatic renal cell carcinoma patients. Clin Cancer Res 15: 4986-4992, 2009. PMID: 19622576. DOI: 10.1158/1078-0432.CCR-08-3240

11 Berntsen A, Trepiakas R, Wenandy L, Geertsen PF, thor Straten $\mathrm{P}$, Andersen MH, Pedersen AE, Claesson MH, Lorentzen T, Johansen JS and Svane IM: Therapeutic dendritic cell vaccination of patients with metastatic renal cell carcinoma: A clinical phase 1/2 trial. J Immunother 1997 31: 771-780, 2008. PMID: 18779742. DOI: 10.1097/CJI.0b013e3181833818

12 Kim JH, Lee Y, Bae Y-S, Kim WS, Kim K, Im HY, Kang WK, Park K, Choi HY, Lee HM, Baek S-Y, Lee H, Doh H, Kim BM, Kim CY, Jeon C and Jung CW: Phase I/II study of immunotherapy using autologous tumor lysate-pulsed dendritic cells in patients with metastatic renal cell carcinoma. Clin Immunol 125: 257-267, 2007. PMID: 17916447. DOI: 10.1016/ j.clim.2007.07.014

13 Pal SK, Hu A and Figlin RA: A new age for vaccine therapy in renal cell carcinoma. Cancer J 19: 365-370, 2013. PMID 23867519. DOI: 10.1097/PPO.0b013e31829d74b4

$14 \mathrm{Su}$ Z, Dannull J, Heiser A, Yancey D, Pruitt S, Madden J, Coleman D, Niedzwiecki D, Gilboa E and Vieweg J: Immunological and clinical responses in metastatic renal cancer patients vaccinated with tumor RNA-transfected dendritic cells. Cancer Res 63: 2127-2133, 2003. PMID: 12727829.

15 Schoenberger SP, Toes RE, van der Voort EI, Offringa R and Melief CJ: T-cell help for cytotoxic T-lymphocytes is mediated by CD40-CD40L interactions. Nature 393: 480-483, 1998. PMID: 9624005. DOI: 10.1038/31002

16 Anguille S, Smits EL, Lion E, van Tendeloo VF and Berneman $\mathrm{ZN}$ : Clinical use of dendritic cells for cancer therapy. Lancet
Oncol 15: e257-267, 2014. PMID: 24872109. DOI: 10.1016/ S1470-2045(13)70585-0

17 Fallaux FJ, Kranenburg O, Cramer SJ, Houweling A, Van Ormondt H, Hoeben RC and Van Der Eb AJ: Characterization of 911: A new helper cell line for the titration and propagation of early region 1-deleted adenoviral vectors. Hum Gene Ther 7: 215222, 1996. PMID: 8788172. DOI: 10.1089/hum.1996.7.2-215

18 González-Carmona MA, Märten A, Hoffmann P, Schneider C, Sievers E, Schmidt-Wolf IGH, Sauerbruch T and Caselmann WH: Patient-derived dendritic cells transduced with an $\alpha$-fetoproteinencoding adenovirus and co-cultured with autologous cytokineinduced lymphocytes induce a specific and strong immune response against hepatocellular carcinoma cells. Liver Int 26: 369-379, 2006. PMID: 16584401. DOI: 10.1111/j.1478-3231.2005.01235.x

19 Graham FL and Prevec L: Methods for construction of adenovirus vectors. Mol Biotechnol 3: 207-220, 1995. PMID: 7552690. DOI: $10.1007 / \mathrm{BF} 02789331$

20 Märten A, Renoth S, Heinicke T, Albers P, Pauli A, Mey U, Caspari R, Flieger D, Hanfland P, Von Ruecker A, Eis-Hübinger AM, Müller S, Schwaner I, Lohmann U, Heylmann G, Sauerbruch T and Schmidt-Wolf IGH: Allogeneic dendritic cells fused with tumor cells: Preclinical results and outcome of a clinical phase I/II trial in patients with metastatic renal cell carcinoma. Hum Gene Ther 14: 483-494, 2003. PMID: 12691613. DOI: $10.1089 / 104303403321467243$

21 Laurell A, Lönnemark M, Brekkan E, Magnusson A, Tolf A, Wallgren AC, Andersson B, Adamson L, Kiessling R and Karlsson-Parra A: Intratumorally injected pro-inflammatory allogeneic dendritic cells as immune enhancers: A first-in-human study in unfavourable risk patients with metastatic renal cell carcinoma. J Immunother Cancer 5: 52, 2017. PMID: 28642820. DOI: $10.1186 / \mathrm{s} 40425-017-0255-0$

22 Wang D, Zhang B, Gao H, Ding G, Wu Q, Zhang J, Liao L and Chen H: Clinical research of genetically modified dendritic cells in combination with cytokine-induced killer cell treatment in advanced renal cancer. BMC Cancer 14: 251, 2014. PMID: 24720900. DOI: 10.1186/1471-2407-14-251

23 Amin A, Dudek AZ, Logan TF, Lance RS, Holzbeierlein JM, Knox JJ, Master VA, Pal SK, Miller WH, Karsh LI, Tcherepanova IY, DeBenedette MA, Williams WL, Plessinger DCs, Nicolette CA and Figlin RA: Survival with AGS-003, an autologous dendritic cellbased immunotherapy, in combination with sunitinib in unfavorable risk patients with advanced renal cell carcinoma (RCC): Phase 2 study results. J Immunother Cancer 3: 14, 2015. PMID: 25901286. DOI: 10.1186/s40425-015-0055-3

24 Figlin RA: Personalized immunotherapy (AGS-003) when combined with sunitinib for the treatment of metastatic renal cell carcinoma. Expert Opin Biol Ther 15: 1241-1248, 2015. PMID: 26125651. DOI: $10.1517 / 14712598.2015 .1063610$

25 Guo Z, Gao H-Y, Zhang T-Y, Lou J-X, Yang K, Liu X-D, He X$\mathrm{P}$ and Chen H-R: Adenovirus co-expressing CD40 ligand and interleukin (IL)-2 contributes to maturation of dendritic cells and production of IL-12. Biomed Rep 5: 567-573, 2016. PMID: 27882218. DOI: $10.3892 /$ br.2016.773

26 Zafar S, Parviainen S, Siurala M, Hemminki O, Havunen R, Tähtinen S, Bramante S, Vassilev L, Wang H, Lieber A, Hemmi S, de Gruijl T, Kanerva A and Hemminki A: Intravenously usable fully serotype 3 oncolytic adenovirus coding for CD40L as an enabler of dendritic cell therapy. Oncoimmunology 6: e1265717, 2017. PMID: 28344872. DOI: 10.1080/2162402X. 2016.1265717 
27 Molinier-Frenkel V, Prévost-Blondel A, Hong S-S, Lengagne R, Boudaly S, Magnusson MK, Boulanger P and Guillet J-G: The maturation of murine dendritic cells induced by human adenovirus is mediated by the fiber knob domain. J Biol Chem 278: 3717537182, 2003. PMID: 12855705. DOI: $10.1074 /$ jbc. M303496200

28 Basner-Tschakarjan E, Gaffal E, O'Keeffe M, Tormo D, Limmer A, Wagner $\mathrm{H}$, Hochrein $\mathrm{H}$ and Tüting $\mathrm{T}$ : Adenovirus efficiently transduces plasmacytoid dendritic cells resulting in TLR9dependent maturation and IFN-alpha production. J Gene Med 8: 1300-1306, 2006. PMID: 16952196. DOI: 10.1002/jgm.964

29 Loskog A, Tötterman TH, Böhle A and Brandau S: In vitro activation of cancer patient-derived dendritic cells by tumor cells genetically modified to express CD154. Cancer Gene Ther 9: 846-853, 2002. PMID: 12224026. DOI: 10.1038/sj.cgt.7700507

30 Palucka $\mathrm{K}$ and Banchereau J: Cancer immunotherapy via dendritic cells. Nat Rev Cancer 12: 265-277, 2012. PMID: 22437871. DOI: $10.1038 / \mathrm{nrc} 3258$

31 Banchereau J and Palucka AK: Dendritic cells as therapeutic vaccines against cancer. Nat Rev Immunol 5: 296-306, 2005. PMID: 15803149. DOI: $10.1038 /$ nri1592

32 Gabrilovich D: Mechanisms and functional significance of tumour-induced dendritic-cell defects. Nat Rev Immunol 4: 941952, 2004. PMID: 15573129. DOI: 10.1038/nri1498

33 Lee J-K, Seki N, Sayers TJ, Subleski J, Gruys EM, Murphy WJ and Wiltrout RH: Constitutive expression of functional CD40 on mouse renal cancer cells: Induction of Fas and Fas-mediated killing by CD40L. Cell Immunol 235: 145-152, 2005. PMID: 16213477. DOI: $10.1016 /$ j.cellimm.2005.08.029

34 Pen JJ, De Keersmaecker B, Maenhout SK, Van Nuffel AMT, Heirman C, Corthals J, Escors D, Bonehill A, Thielemans K, Breckpot $\mathrm{K}$ and Aerts JL: Modulation of regulatory T-cell function by monocyte-derived dendritic cells matured through electroporation with mRNA encoding CD40 ligand, constitutively active TLR4, and CD70. J Immunol 191: 19761983, 2013. PMID: 23842750. DOI: 10.4049/jimmunol.1201008

35 Weiss JM, Gregory Alvord W, Quiñones OA, Stauffer JK and Wiltrout RH: CD40 expression in renal cell carcinoma is associated with tumor apoptosis, CD8(+) T-cell frequency and patient survival. Hum Immunol 75: 614-620, 2014. PMID: 24801648. DOI: $10.1016 /$ j.humimm.2014.04.018
36 Schmidt-Wolf IG, Lefterova P, Mehta BA, Fernandez LP, Huhn D, Blume KG, Weissman IL and Negrin RS: Phenotypic characterization and identification of effector cells involved in tumor cell recognition of cytokine-induced killer cells. Exp Hematol 21: 1673-1679, 1993. PMID: 7694868.

37 Jäkel CE, Hauser S, Rogenhofer S, Müller SC, Brossart P and Schmidt-Wolf IGH: Clinical studies applying cytokine-induced killer cells for the treatment of renal cell carcinoma. Clin Dev Immunol 2012: 473245, 2012. PMID: 23193418. DOI: 10.1155/ 2012/473245

38 Schmeel LC, Schmeel FC, Coch C and Schmidt-Wolf IGH: Cytokine-induced killer (CIK) cells in cancer immunotherapy: Report of the International Registry on CIK Cells (IRCC). J Cancer Res Clin Oncol 141: 839-849, 2015. PMID: 25381063. DOI: $10.1007 / \mathrm{s} 00432-014-1864-3$

39 Schmidt-Wolf IG, Finke S, Trojaneck B, Denkena A, Lefterova P, Schwella N, Heuft HG, Prange G, Korte M, Takeya M, Dorbic T, Neubauer A, Wittig B and Huhn D: Phase I clinical study applying autologous immunological effector cells transfected with the interleukin-2 gene in patients with metastatic renal cancer, colorectal cancer and lymphoma. Br J Cancer 81: 10091016, 1999. PMID: 10576658. DOI: 10.1038/sj.bjc.6690800

40 Schmidt-Wolf IG, Negrin RS, Kiem HP, Blume KG and Weissman IL: Use of a SCID mouse/human lymphoma model to evaluate cytokine-induced killer cells with potent antitumor cell activity. J Exp Med 174: 139-149, 1991. PMID: 1711560. 